\title{
Overexpression of a Long Non-Coding RNA BC037916 is Associated with Pancreatic Tumorigenesis and Poor Prognosis
}

This article was published in the following Dove Press journal: OncoTargets and Therapy

\author{
Gang Chen' \\ Litao $\mathrm{Xu}^{2,3}$ \\ Guanxiong $\mathrm{Ye}^{4}$ \\ Junhua $\operatorname{Lin}^{2,3}$ \\ Zhiqiang Meng ${ }^{2,3}$ \\ Yehua Shen ${ }^{2,3}$ \\ 'Department of Pediatric Cardiothoracic \\ Surgery, Children's Hospital of Fudan \\ University, Shanghai, People's Republic of \\ China; ${ }^{2}$ Department of Integrative \\ Oncology, Fudan University Shanghai \\ Cancer Center, Shanghai, China; \\ ${ }^{3}$ Department of Oncology, Shanghai \\ Medical College, Fudan University, \\ Shanghai, People's Republic of China; \\ ${ }^{4}$ Department of Hepatobiliary Surgery, \\ People's Hospital of Lishui, The Sixth \\ Affiliated Hospital of Wenzhou Medical \\ University, Lishui, People's Republic of \\ China
}

Background: Pancreatic cancer is one of the most lethal malignancies. Accumulating evidence supports for the critical contribution of long noncoding RNAs (lncRNAs) to the cancer development and progression. We tried to identify novel lncRNAs involved in the pancreatic carcinogenesis.

Materials and Methods: Two independent datasets (Gene Expression Omnibus datasets: GSE16515 and GSE32688) were obtained from the Gene Expression Omnibus (GEO). The level of BC037916 was detected in pancreatic cancer tissues and adjacent no-tumorous tissues ( $\mathrm{n}=86$ ) by qRT-PCR. Effects of BC037916 on proliferation, apoptosis, and invasion of pancreatic cancer cells were examined.

Results: We identified a novel lncRNA BC037916 involved in the pancreatic carcinogenesis by analyzing GEO datasets. Quantitative RT-PCR analysis showed that 86.0\% (74/86) pancreatic cancer tissues had increased BC037916 expression as compared with normal counterparts. Further, positive correlation was observed between BC037916 expression and clinical stage, primary tumor, and regional lymph node invasion. Importantly, BC037916 was an independent prognostic factor of pancreatic cancer. Functionally, knockdown of BC037916 repressed cell proliferation, inhibited cell invasion, halted cell cycle progression, and promoted apoptosis in both PANC-1 and SW1990 cells. In contrast, overexpression of BC037916 in CAPAN-1 had opposite effects. Moreover, silencing of BC037916 significantly inhibited the tumor growth of xenografted SW1990 cells in vivo. Results of Western blot assays suggested that BC037916 knockdown also suppressed the activation of JAK2/STAT3 and TGF- $\beta$ signaling. Further experiments suggested that BC037916 positively regulated the expression of Twist through miR-3145-3p.

Conclusion: BC037916 exhibited oncogenic potential in pancreatic cancer development. Keywords: lncRNA, pancreatic cancer, JAK2/STAT3, TGF- $\beta$

\section{Background}

Pancreatic carcinoma is the fourth leading disease-related cause of death globally. ${ }^{1}$ Although the underlying causes of pancreatic cancer have not been fully understood, certain risk factors, including smoking, obesity, diabetes, age, and genetic conditions, have been identified. ${ }^{2}$ Due to the lack of useful biomarkers and effective early detection methods, most cases of pancreatic cancer are diagnosed in advanced stages, which lead to the devastatingly poor prognosis of pancreatic cancer patients. ${ }^{1,3,4}$ Hence, there is an urgency for identification of novel prognostic biomarkers and targets and development of better therapeutic options to accelerate the diagnosis and improve the treatment of pancreatic carcinoma.
Correspondence: Yehua Shen 270 Dong'An Road, Shanghai 200032 People's Republic of China $\mathrm{Tel}+(86) 21-64175590-83625$ Email yehuash25@yeah.net
OncoTargets and Therapy 2020:13 1345I-13463

$\mid 345$ |

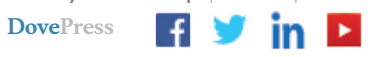

http://doi.org/10.2147/0TTS282350 
Recent next-generation sequencing studies have identified that the majority of human transcriptome is recognized as non-coding RNAs (ncRNAs), which are further categorized into small ( $<200 \mathrm{nt}$ in length) and long non-coding RNAs (lncRNAs, $>200 \mathrm{nt}$ in length). ${ }^{5}$ LncRNAs have attracted increasing scientific interest and increasing data have shown the important role of IncRNAs in a spectrum of cellular processes such as cell survival, ${ }^{6}$ cell cycle,,${ }^{7,8}$ migration, ${ }^{9,10}$ and metabolism. ${ }^{11}$ Dysregulated lncRNAs have been detected in many complicated human diseases including human cancers, indicating that lncRNAs may be critical players in the development and progression of cancer. $^{12-20}$

In pancreatic cancer, aberrant expression of IncRNAs, such as HOTAIR, ${ }^{19}$ MALAT $1,{ }^{20}$ and CRNDE $^{21}$ have been shown. LncRNA MALAT1 was up-regulated and overexpression of MALAT1 serves a marker for an unfavorable prognosis. $^{20}$ Knockdown of lncRNA HOTAIR $^{19}$ or HOTTIP $^{12}$ inhibited proliferation and inhibited invasion of pancreatic cancer cells. However, it is estimated that there are approximately 15,000 lncRNAs in humans ${ }^{22}$ and IncRNA profiles in pancreatic cancer remain largely unknown. In the current study, two independent datasets (GSE16515 $5^{23}$ and GSE32688) were obtained from the Gene Expression Omnibus (GEO), and lncRNAs profiling was accomplished by Genomic and Transcriptomic Explorer (GATExplorer). ${ }^{24}$ IncRNA BC037916 was identified as a candidate pro-oncogene in pancreatic cancer. We then explored its expression profiles and clinical implication in pancreatic cancer tissues and investigated its biological function during tumor progression.

\section{Materials and Methods}

\section{Microarray and IncRNA Profile Mining}

Microarray datasets from GSE16515 ${ }^{23}$ and GSE32688 were acquired from GEO (http://www.ncbi.nlm.nih.gov/ geo/). GSE16515 consisted of 36 pancreatic tumor samples and 16 normal samples, while GSE32688 consisted of 25 pancreatic tumor samples and 7 normal samples. GATExplorer $^{24}$ was used to process microarrays for gene expressions of $\operatorname{lncRNAs}$ as previously described. ${ }^{25}$

\section{Tissue Collection and RNA Extraction}

This study was in accordance with the local Research Ethics Committee approval. A total of 86 patients admitted at People Hospital of Lishui, the Sixth Affiliated Hospital of Wenzhou Medical University (Zhejiang, China) from
January 2007 to June 2010 were enrolled in this study after written informed consent was acquired. Patients had never undergone chemotherapy, radiation therapy, or any other types of anti-cancer therapies prior to surgery. The clinical stages were determined in compliance with the American Joint Committee on Cancer (AJCC) staging system. Pairs of on-site tumor tissues and adjacent non-tumor tissues were preserved and stored at $-80^{\circ} \mathrm{C}$. Overall survival (OS) was calculated from the dates of surgery to decrease (in month). RNA was isolated from the tissue samples using Trizol (Invitrogen, Carlsbad, CA USA) as per manufacturer's guidance.

\section{Quantitative Real-Time PCR (qRT-PCR)}

qRT-PCR was conducted to determine expression levels of BC037916, miRNAs, and Twist using the SYBR Green Kit (Thermo Fisher Scientific, Waltham, MA, USA) and ABI 7300 System (Applied Biosystems, Foster City, CA, USA). The primers were listed in Supplemental Table S1. LncRNA and Twist expression was normalized to GAPDH, while miRNA expression was normalized to U6 small nuclear 1 (RNU6-1) using the formula $2^{-\Delta \Delta \mathrm{CT}}$.

\section{Cell Lines}

A normal pancreatic duct epithelial cell line, HPDE6-C7, and five pancreatic cancer cell lines (BXPC3, SW1990, PANC-1, CAPAN-1, and ASPC-1) were acquired from the Shanghai Cell Bank (Shanghai, China). Cells were maintained in Dulbecco's modified Eagle's medium (DMEM, Invitrogen) containing 10\% fetal bovine serum (FBS, Hyclone, Logan, UT, USA) and antibiotics in tissue culture incubators.

\section{RNA Interference and Plasmid Transfection}

Four siRNAs targeting human BC037916 (siRNA1, GAC GCT ATT CTA AGG ACC ATA; siRNA2, GTA GAA GAG CTA AGT GAA ATG; siRNA3, GCA GTC TTA GAG GGT TTG AGG; siRNA4, GCA GAG GGT AAT ACC AAT ACT) and one negative control siRNA (siNC) were obtained from Genepharma (Shanghai, China). The BC037916 full sequence was cloned into the pcDNA3.1 vector (Invitrogen). Knockdown and overexpression of BC037916 in pancreatic cancer cells was performed by transfection using Lipofectamine 2000 (Invitrogen) as per the manufacturer's instruction. 


\section{Western Blotting}

Protein lysates were prepared in RIPA buffer supplemented with protease inhibitor cocktails (Sigma, St. Louis, MO, USA) by centrifugation. A total of $30-40 \mu \mathrm{g}$ of total protein resolved by $10 \%$ or $15 \%$ SDS-PAGE gels was blotted onto nitrocellulose membranes. After $30 \mathrm{~min}$ of blocking with $5 \%$ nonfat milk at room temperature, membranes were incubated with primary antibodies at $4^{\circ}$ Covernight. Following incubation with horseradish peroxidase (HRP)conjugated secondary antibody (Beyotime, Shanghai, China), enhanced chemiluminescence (ECL) (Bio-Rad, Hercules, CA, USA) was added to membrane for developing. Primary antibodies against PCNA, Cyclin D, Twist, MMP-2, MMP-9, pSTAT3, STAT3, and psmad2/3 were purchased from Abcam (Cambridge, United Kingdom). Antibodies for E-cadherin, b-catenin, pJAK2, JAK2 and $\operatorname{smad} 2 / 3$ and GAPDH were obtained from Cell Signaling Technology (Danvers, MA, USA). Anti-Bcl-2 and anti-Bax were from Santa Cruz Biotechnology (Dallas, TX, USA).

\section{Cell Proliferation Assay}

Cells were plated in 96 -well plates $\left(3 \times 10^{3} /\right.$ well $)$, and either siRNA or IncRNA expression plasmid was transfected to cells. $0 \mathrm{~h}, 24 \mathrm{~h}, 48 \mathrm{~h}$, and $72 \mathrm{~h}$ after transfection, Cell Count Kit-8 (CCK-8, Dojindo Laboratories, Tokyo, Japan) reagent was added and incubated at $37^{\circ} \mathrm{C}$ for 1 h. Absorbance at $450 \mathrm{~nm}$ was recorded using a plate reader (BioRad, Hercules, CA, USA).

\section{Flow Cytometry Analyses of Cell Cycle and Apoptosis}

At $48 \mathrm{~h}$ after transfection, cells were collected and washed once with ice-cold PBS. To assess cell cycle distribution, the cells were fixed in cold $70 \%$ ethanol at $-20^{\circ} \mathrm{C}$ overnight, and washed twice with ice-cold PBS, then stained with $0.1 \mathrm{mg} / \mathrm{mL}$ propidium iodide (PI, Sigma) and $1 \mathrm{mg} /$ $\mathrm{mL}$ RNase $\mathrm{A}$ at $37^{\circ} \mathrm{C}$ for $30 \mathrm{~min}$. For cell apoptosis assay, the collected cells were stained with PI and annexin V-fluorescein isothiocyanate (FITC) (KeyGEN Biotech, Nanjing, China) at room temperature for $20 \mathrm{~min}$. Cell cycle distribution and cell apoptosis were evaluated by the FACScan flow cytometer (BD Biosciences, San Jose, CA, USA).

\section{Cell Invasion Assay}

Cells were harvested 24 hours post-transfection, resuspended with serum-free DMEM medium, and plated in 24- well Matrigel invasion chambers ( $8 \mu \mathrm{m}$; BD Biosciences) at a density of $5 \times 10^{4} /$ well. DMEM supplemented with $10 \%$ FBS as a chemoattractant was added to the bottom chamber. The noninvasive cells were carefully removed using a cotton swab at $48 \mathrm{~h}$ post incubation. After fixing with $4 \%$ paraformaldehyde, invasive cells were enumerated by staining with $0.2 \%$ crystal violet and microscopy.

\section{miRNA Transfection}

miR3145-3p mimic (5'-AGAUAUUUUGAGUGUUUGG AAUUG-3'), inhibitor (5'-CAAUUCCAAACACUCAAAA UAUCU-3') and control (5'-CAGUACUUUUGUGUAGUA CAA-3') were synthesized by Genepharm Technologies (Shanghai, China). Transfection was carried out using the Lipofectamine 2000 reagent (Invitrogen) according to the manufacturer's instructions.

\section{Luciferase Reporter Assay}

The full-length human Twist wild-type (WT) 3'-untranslated region (3'-UTR) fragment and mutant $3^{\prime}$ UTR fragment with mutation in the putative miR-3145-3p binding sites were inserted into pGL3 Vector (Promega, Madison, WI). Luciferase activity was detected using the Dual-Luciferase Reporter Assay System (Promega).

\section{Subcutaneous Xenografts in Nude Mice}

Animal studies were conducted in compliance with the guidelines of the Animal Care and Use Committee of Fudan University Shanghai Cancer Center. Eight weeks old male athymic $\mathrm{BALB} / \mathrm{c}$ nude mice were acquired from Slac Laboratory Animal Co. Ltd. (Shanghai, China). SW1990 cells transfected with siNC or siRNA4 were collected and subcutaneously (s.c.) injected into flanks of the mice $\left(5 \times 10^{6} \%\right.$ $0.1 \mathrm{~mL}$ PBS). The mice were administered with siNC or siRNA4 containing formulations, respectively, via tail vein twice a week. Subcutaneous tumor volumes (V) were measured every three days with digital calipers and determined from the equation: $\mathrm{V}=\left(\right.$ length $\times$ width $\left.^{2}\right) / 2$. After 46 days, all mice were euthanized and tumors were harvested.

\section{Statistical Analysis}

Data were analyzed by SPSS software (v16.0, SPSS, Inc., Chicago, IL, USA) and shown as mean \pm standard deviation (SD). Student's $t$-test was carried out to compare the differences between the two groups. The clinical characteristics of tumors with differential BC037916 expression were determined by the Chi-square tests. Cox regression model was employed to determine univariate and 
multivariate hazard ratios. Patients' survival analyses were carried out using Kaplan-Meier analysis and Log-rank test. $P<0.05$ represents statistical significance, with significance annotated as follows: ${ }^{*} P<0.05, * * P<0.01$, and $* * P<0.001$.

\section{Results}

\section{Screen of Pancreatic Cancer-Specific LncRNA}

To characterize differentially expressed lncRNAs between pancreatic cancer tissues and normal tissues, GSE16515 (Figure 1A) and GSE32688 datasets (Figure 1B) were analyzed by Arraytools. The expression of lncRNA BC037916 is extremely higher in pancreatic cancer tissues than in normal tissues in both datasets $(P<0.001)$.

\section{BC037916 Was Overexpressed in} Pancreatic Cancer

We then performed qRT-PCR to assess the expression of IncRNA BC037916 in 86 pairs of pancreatic tumor tissues and adjacent normal tissues collected from our own hospital and found that BC037916 expression was dramatically elevated in $86.0 \%(74 / 86)$ cancerous tissues in comparison with corresponding normal tissues $(P<0.0001)$ (Figure 1C).

\section{Correlation Analysis Between BC037916 Expression and the Clinical Parameters of} Pancreatic Cancer

The 86 pancreatic cancer tissues were divided into BC037916 high expression group and BC037916 low expression group as values above and below the median, respectively (Figure 1D). We then explored the clinical relevance of $\mathrm{BC} 037916$ expression in pancreatic cancer by examining the association between its expression and patients' clinical characteristics. As shown in Table 1, increased BC037916 expression was strongly related to clinical stage $(P=0.0202)$, primary tumor $(P=0.0164)$ and regional lymph node invasion $(P=0.0225)$, but not with other clinical parameters.

\section{BC0379I6 Serves as an Independent Prognostic Factor for Pancreatic Cancer}

Univariate analysis was conducted and four prognostic factors, BC037916 expression (high vs low), clinical stage (I-II vs III-IV), primary tumor (T1-2 vs T3-4) and regional lymph node invasion (N0 vs N1) were identified as statistically indicative prognosis factors (Table 2). Further multivariate analysis revealed that these four factors may serve as prognostic factors for poor OS independently. Kaplan-Meier survival curves in Figure 1E showed that patients with higher BC037916 expression had inferior OS compared with those with lower expression $(P<0.0001)$.

\section{BC037916 Expression in Pancreatic Cancer Cells}

BC037916 expression in pancreatic cancer cell lines (BXPC3, SW1990, PANC-1, CAPAN-1, and ASPC-1) and a normal pancreatic duct epithelial cell line (HPDE6C7) was assessed by qRT-PCR. As illustrated in Figure 2A, BC037916 expression was remarkably elevated in pancreatic cancer cells than in HPDE6-C7. Two cell lines, SW1990 and PANC-1, showing higher BC037916 expression were chosen for RNAi experiment. On the contrary, CAPAN-1 that has lower BC037916 expression was chosen for overexpression experiment.

\section{Effect of BC037916 Expression Level on Cell Proliferation}

Four siRNAs specific to BC037916 (siRNA1-4) and a control siRNA (siNC) were transfected into SW1990 and PANC-1cells. qRT-PCR assay revealed that siRNAs transfection significantly reduced the expression of BC037916 in both cell lines (Figure 2B). siRNA4 was the most effective one and chosen for the subsequent experiments. BC037916 was forced overexpressed in CAPAN-1 cells by transfection with plasmid expressing BC037916 (Figure 2C).

To investigate the potential function of BC037916 in pancreatic carcinogenesis, CCK-8 assay was conducted to assess the cell proliferation based on BC037916 expression levels. The results demonstrated that silencing of BC037916 by siRNA4 (Figure 2D) or siRNA3 (Supplemental Figure S1A) significantly repressed cell proliferation in both SW1990 and PANC-1 cells when compared with the wild-type (WT) cells and siNC transfected cells (Figure 2D). On the contrary, cell proliferation of CAPAN-1 cells was increased by BC037916 overexpression (Figure 2E).

\section{Effects of BC037916 Expression Level on Cell Cycle Distribution and Cell Apoptosis}

Cell cycle status was then evaluated in BC037916 knocked down and BC037916 overexpressed cells. Flow cytometry (FACS) analyses demonstrated that the percentage of G0/G1 
A

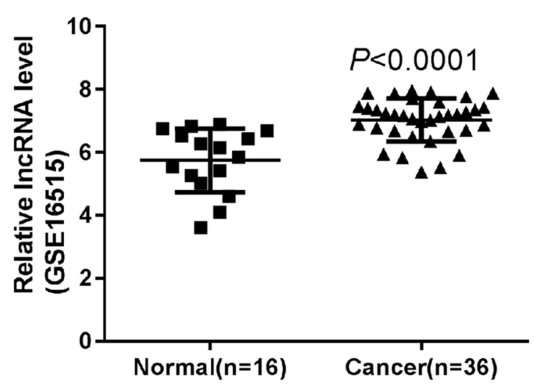

B

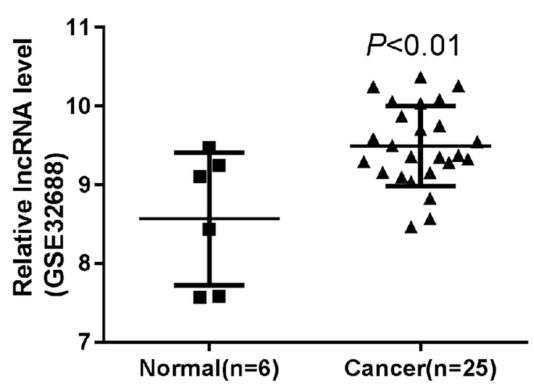

C

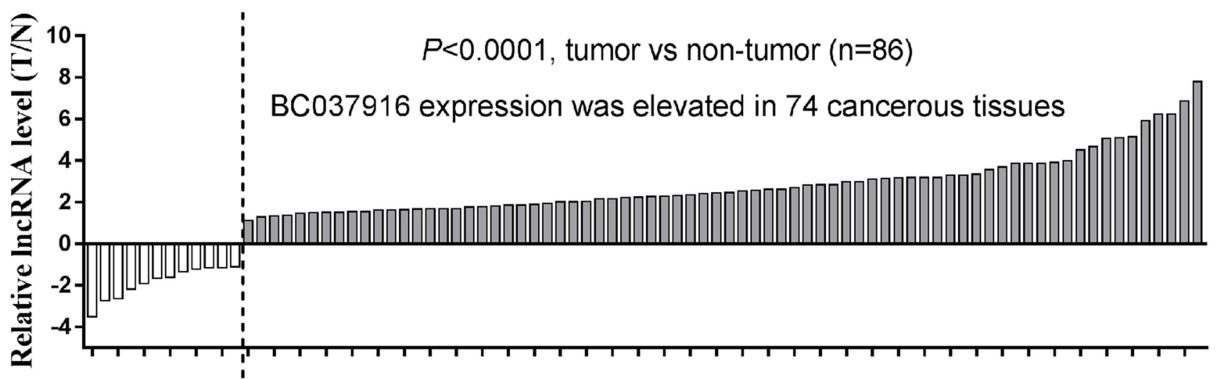

D

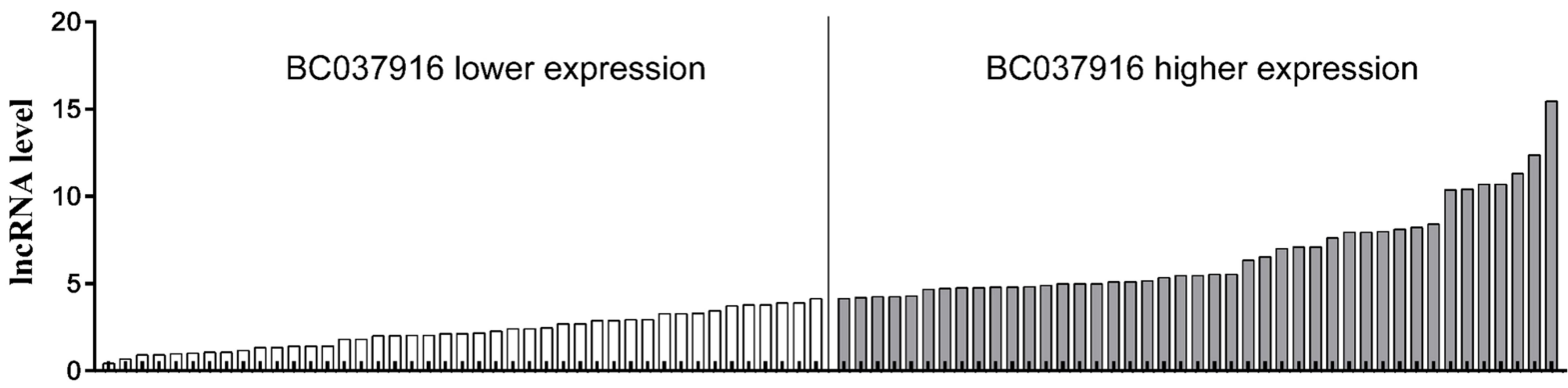

E

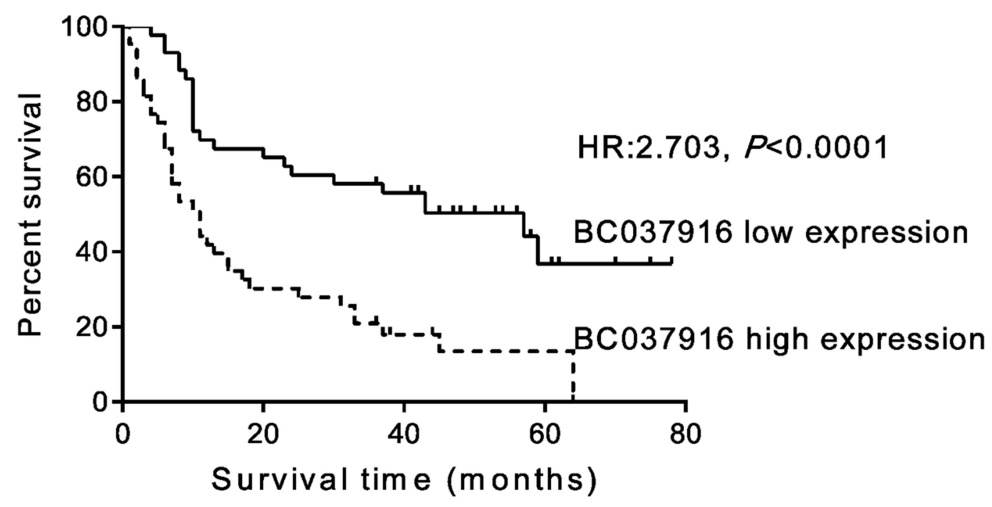

Figure I The expression of IncRNA BC037916 in human pancreatic cancer tissues. (A and B) Screening of pancreatic cancer-specific IncRNA in GEO database. LncRNA BC037916 was consistently elevated in pancreatic cancer tissue compared to the normal tissue in both GSEI65I5 (A) and GSE32688 (B). (C) Relative expression of BC037916 in pancreatic cancer tissues and adjacent non-tumor tissues $(n=86)$ was determined using qRT-PCR followed by normalization to GAPDH. Results are presented as log2 ratios compared to corresponding non-tumor tissues. (D) 86 pancreatic cancer patients were divided into two groups based on IncRNA BC0379I6 expression level. (E) Higher BC0379I6 level was significantly associated with a worse overall survival as indicated by Kaplan-Meier survival curves. 
Table I Correlations Between BC0379/6 Expression and Clinicopathologic Features in Patients with Pancreatic Cancer

\begin{tabular}{|c|c|c|c|c|}
\hline \multirow[t]{2}{*}{$\begin{array}{l}\text { Clinicopathologic } \\
\text { features }\end{array}$} & \multirow[t]{2}{*}{ Total } & \multicolumn{2}{|c|}{$\begin{array}{l}\text { BC037916 } \\
\text { Expression }\end{array}$} & \multirow[t]{2}{*}{$P$ value } \\
\hline & & $\begin{array}{l}\text { Low } \\
(n=43)\end{array}$ & $\begin{array}{l}\text { High } \\
(n=43)\end{array}$ & \\
\hline \multicolumn{5}{|l|}{ Age (years) } \\
\hline$\leq 65$ & 56 & 32 & 24 & 0.1125 \\
\hline$>65$ & 30 & 11 & 19 & \\
\hline \multicolumn{5}{|l|}{ Gender } \\
\hline Male & 50 & 22 & 28 & 0.2744 \\
\hline Female & 36 & 21 & 15 & \\
\hline \multicolumn{5}{|l|}{ Tumor size } \\
\hline$>4 \mathrm{~cm}$ & 35 & 18 & 17 & 1.000 \\
\hline$\leq 4 \mathrm{~cm}$ & 51 & 25 & 26 & \\
\hline \multicolumn{5}{|l|}{ Tumor location } \\
\hline Head & 49 & 25 & 24 & 1.000 \\
\hline Body/tail & 37 & 18 & 17 & \\
\hline \multicolumn{5}{|l|}{ Clinical stage (AJCC) } \\
\hline I-II & 66 & 38 & 28 & $0.0202 *$ \\
\hline III-IV & 20 & 5 & 15 & \\
\hline \multicolumn{5}{|l|}{ T-Primary tumor } \\
\hline TI-T2 & 48 & 30 & 18 & $0.0164 *$ \\
\hline T3-T4 & 38 & 13 & 25 & \\
\hline \multicolumn{5}{|l|}{ 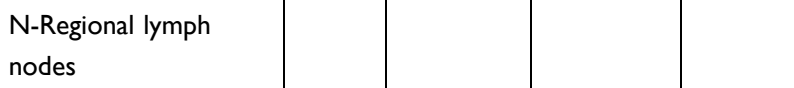 } \\
\hline No & 51 & 31 & 20 & $0.0275^{*}$ \\
\hline $\mathrm{NI}$ & 35 & 12 & 23 & \\
\hline \multicolumn{5}{|l|}{ M-Distant metastasis } \\
\hline Mo & 77 & 40 & 37 & 0.4833 \\
\hline MI & 9 & 3 & 6 & \\
\hline
\end{tabular}

Note: $* P<0.05$. phase was significantly reduced by $31.9 \%(\mathrm{P}<0.01)$, while the percentage of $\mathrm{S}$ phase was notably increased by $85.5 \%$ in PANC-1 cells transfected with BC037916 siRNA4, compared with siNC transfected cells (Figure 2F). Similar results were obtained in SW1990 cells, while complementary results were observed in CAPAN-1 cells overexpressing BC037916 (Figure 2G).

Annexin V-FITC/PI staining and FACS analysis demonstrated that apoptotic ratio was significantly increased in BC037916 knocked down PANC-1 and SW1990 cells (Figure 2H), while BC037916 overexpressed CAPAN-1 cells showed reduced apoptotic ratio (Figure 2I).

\section{Effect of BC037916 Expression Level on Cell Invasion}

Next, we examined the invasive potential of PANC-1 and SW1990 cells transfected with siRNA4 or siRNA3 (Figure 3A and Supplemental Figure S1B), and CAPAN-1 cells overexpressing BC037916 (Figure 3B) by Matrigel invasion assays. The number of invasive cells was remarkably lower in siRNA4 or siRNA3 transfected cells, but notably higher in BC037916 overexpressed CAPAN-1 cells compared with control cells. These data suggested that $\mathrm{BC} 037916$ potentially contributed to the invasion of pancreatic cancer cells.

\section{Downstream Affected by IncRNA BC037916}

To analyze the expression of genes downstream of IncRNA BC037916, Western blotting was performed (Figure 4). In line with in vitro functional characterization, silencing of $\mathrm{BC} 037916$ led to notable decreases in the expression of genes related to cell growth (PCNA and

Table 2 Cox Regression Analysis of BC037916 Expression with Cancer-Specific Mortality in Pancreatic Cancer

\begin{tabular}{|c|c|c|c|c|}
\hline & \multicolumn{2}{|c|}{ Univariate Analysis } & \multicolumn{2}{|c|}{ Multivariate Analysis } \\
\hline & HR (95\% Cl) & $P$ value & HR (95\% Cl) & $P$ value \\
\hline BC0379I6 (high vs low) & $2.81(1.65-4.79)$ & $0.000 * * *$ & $2.13(1.18-3.83$ & $0.012^{*}$ \\
\hline Gender (male vs female) & $0.67(0.39-1.13)$ & 0.133 & & \\
\hline Age $(>65$ vs $\leq 65)$ & $0.78(0.46-1.32)$ & 0.358 & & \\
\hline Tumor Size (>4cm vs $\leq 4 \mathrm{~cm})$ & $\mathrm{I} .20(0.7 \mathrm{I}-2.03)$ & 0.490 & & \\
\hline Tumor location (Head vs bodyandtail) & $1.26(0.76-2.10)$ & 0.377 & & \\
\hline Clinical Stage (I-II vs III-IV) & $2.15(1.22-3.79)$ & $0.008 * *$ & $1.92(I .08-3.4 I)$ & $0.026 *$ \\
\hline T-Primary tumor ( $\mathrm{TI}-2$ vs $\mathrm{T} 3-4)$ & $1.76(1.01-2.93)$ & $0.030 *$ & $1.32(0.77-2.27)$ & 0.315 \\
\hline N-Regional lymph nodes (N0 vs NI) & $2.17(1.30-3.63)$ & $0.003 * *$ & $1.78(1.05-3.04)$ & $0.034^{*}$ \\
\hline M-Distant metastasis (M0 vs MI) & $0.88(0.38-2.04)$ & 0.762 & & \\
\hline
\end{tabular}

Notes: $* P<0.05, * * P<0.01, * * * P<0.001$. 


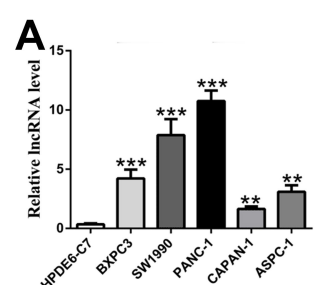

B

D
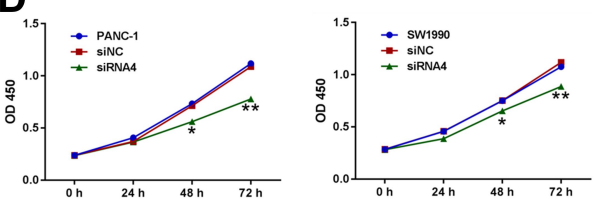

F
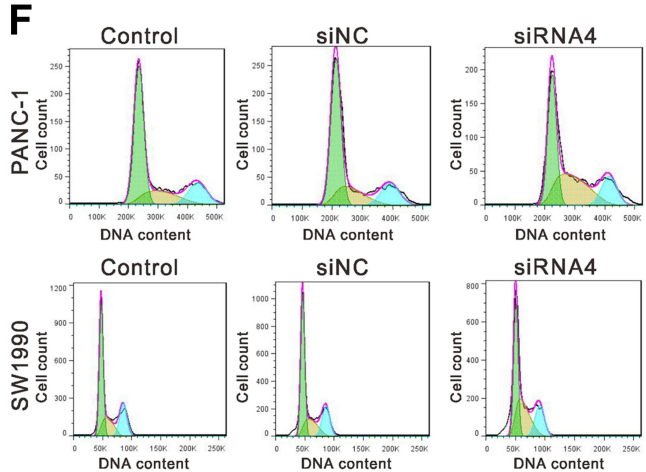

G
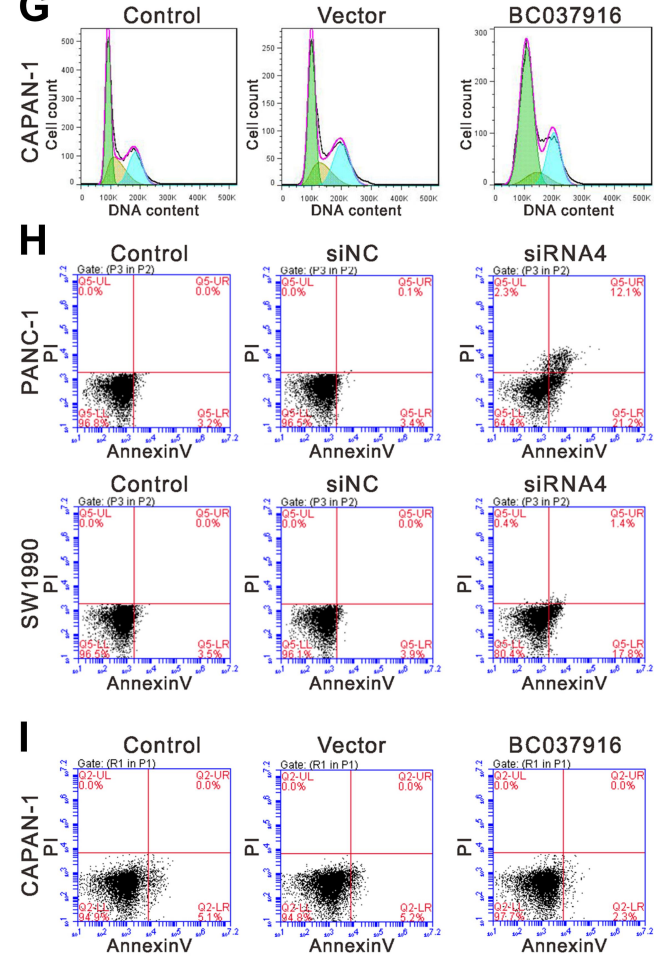

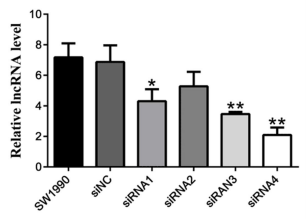

E
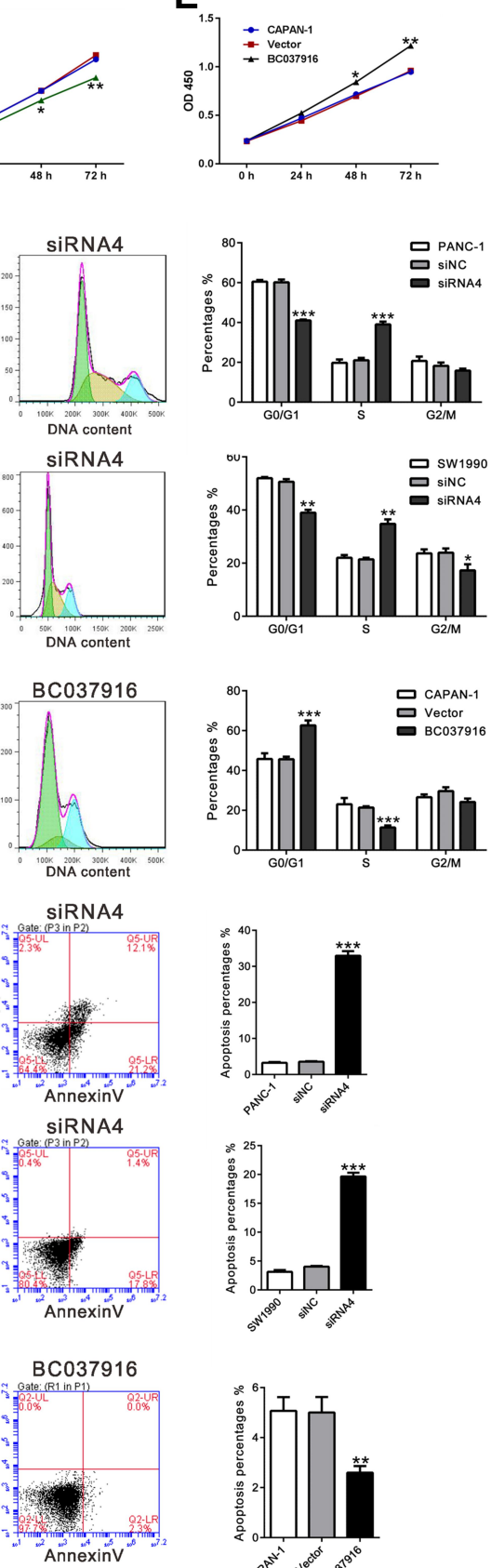
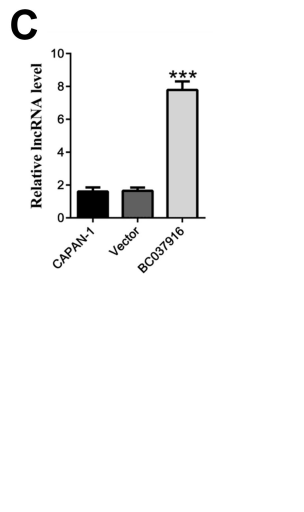
A
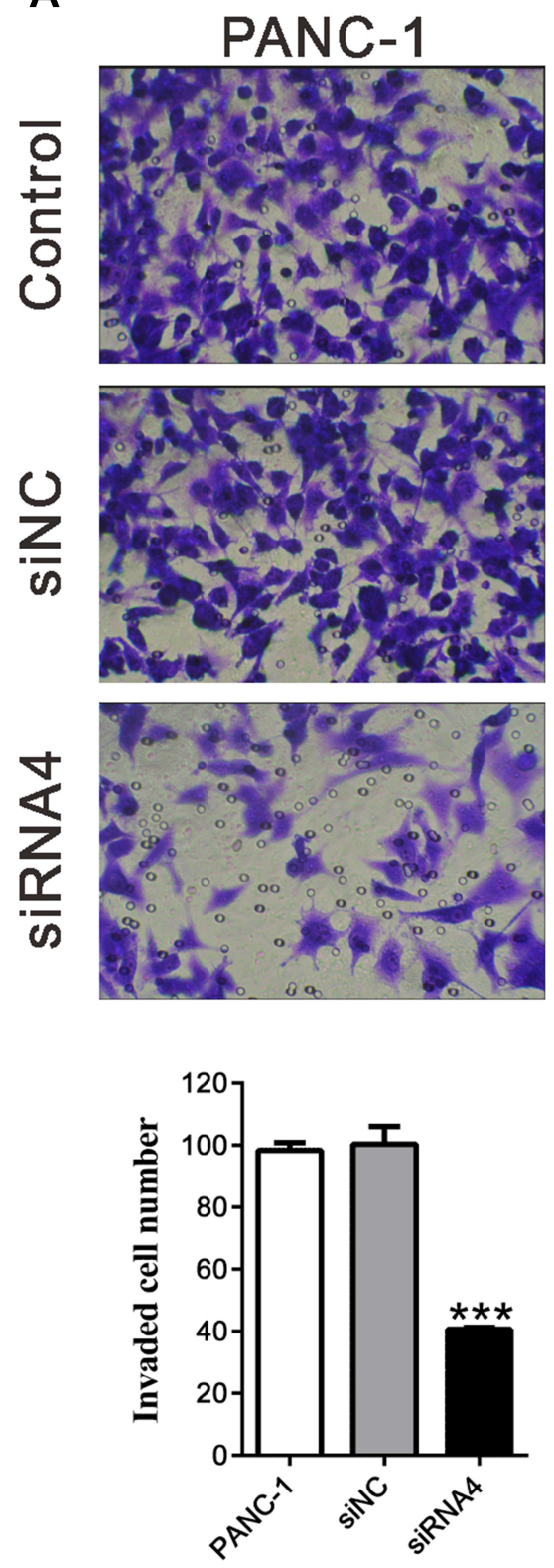

SW1990
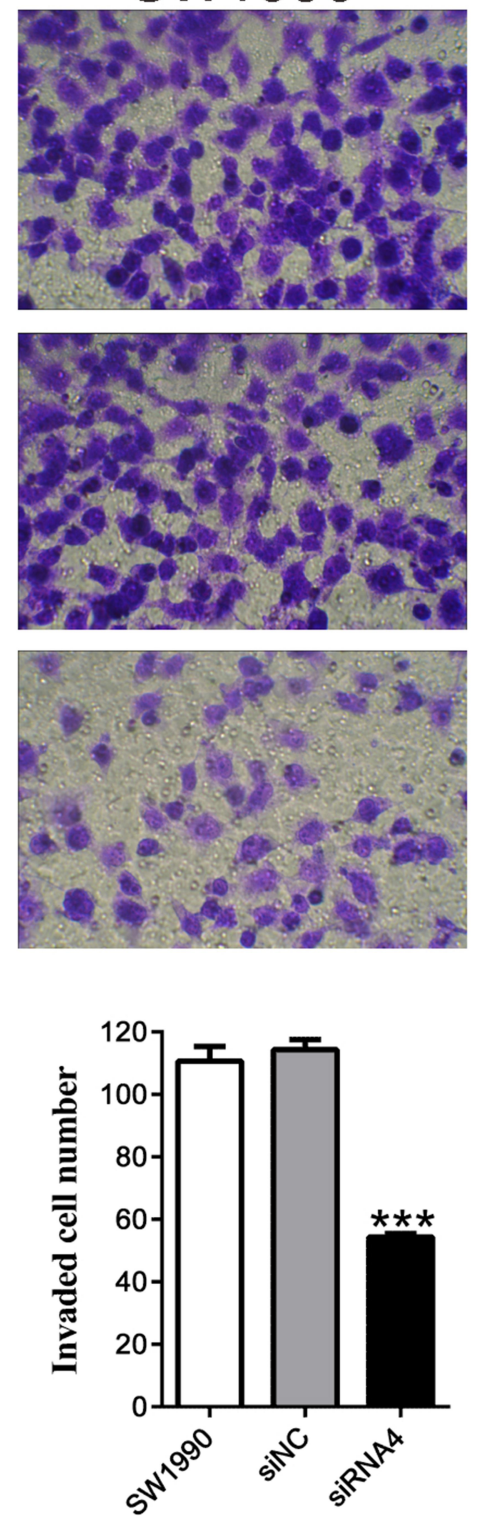

B
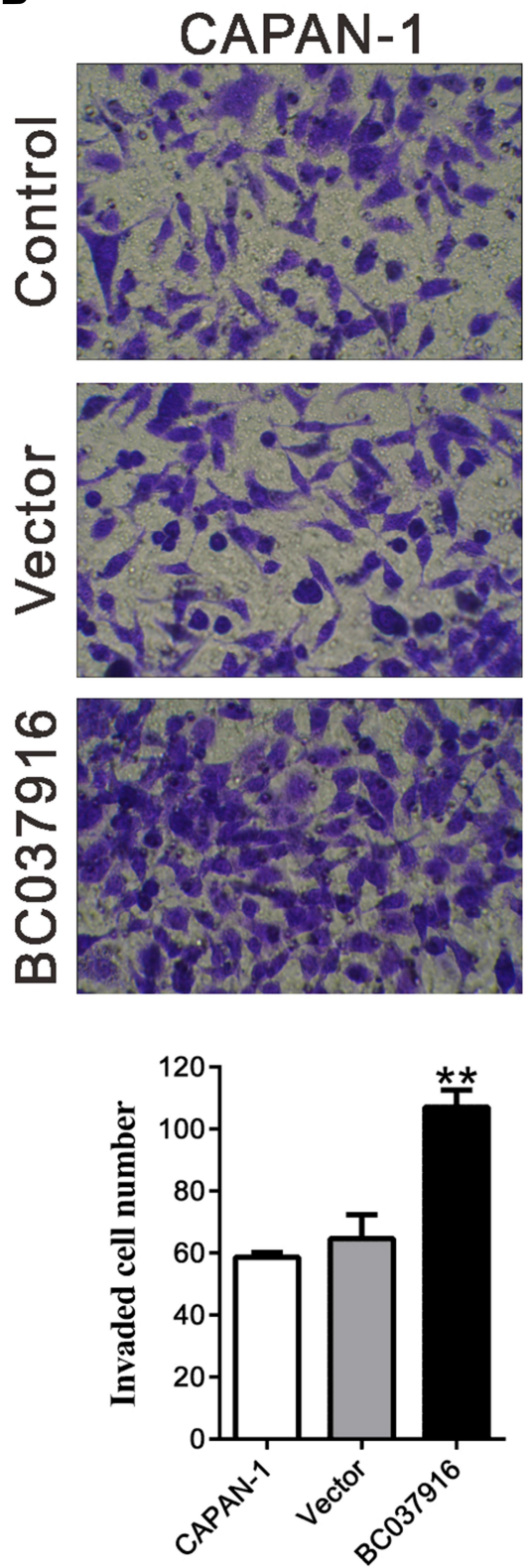

Figure 3 BC0379I6 expression regulates cell invasion. (A) Knockdown of BC0379I6 inhibited the invasion of PANC-I and SWI990 cells. (B) Overexpression of BC0379I6 promoted the invasion of CAPAN-I cells. Magnification: $200 \times$. $* * * P<0.001$ vs siNC; $* * P<0.01$ vs Vector.

Cyclin D), anti-apoptosis (Bcl-2), metastasis (MMP-2 and 9), epithelial-mesenchymal transition (EMT) related factors (Twist and $\beta$-catenin), and a remarkable upregulation in the expression of apoptotic protein Bax and the main factor of EMT (E-cadherin) in PANC-1 and SW1990 cells compared to the control cells.

Moreover, TGF- $\beta$ expression, as well as phosphorylation of JAK2, STAT3, and smad2/3 were significantly decreased in the BC037916 knocked down cells compared with the controls, while JAK2, STAT3, and smad2/3 protein expression were not affected, which indicated that lncRNA
BC037916 may exert its function by inhibition JAK2/ STAT3 and TGF- $\beta /$ smad2/3-mediated signaling pathway.

\section{BC0379I6 Positively Regulated the}

\section{Expression of Twist Through miR-3 I45-3p}

Accumulated evidence indicated that lncRNAs may sequester miRNAs, thereby reducing the binding of endogenous miRNAs to target genes. ${ }^{26}$ By using FINDTAR3 (http://bio. sz.tsinghua.edu.cn/), we found that miR-3145-3p, miR-4482$3 \mathrm{p}$, and miR-12,136 have putative binding sites with 

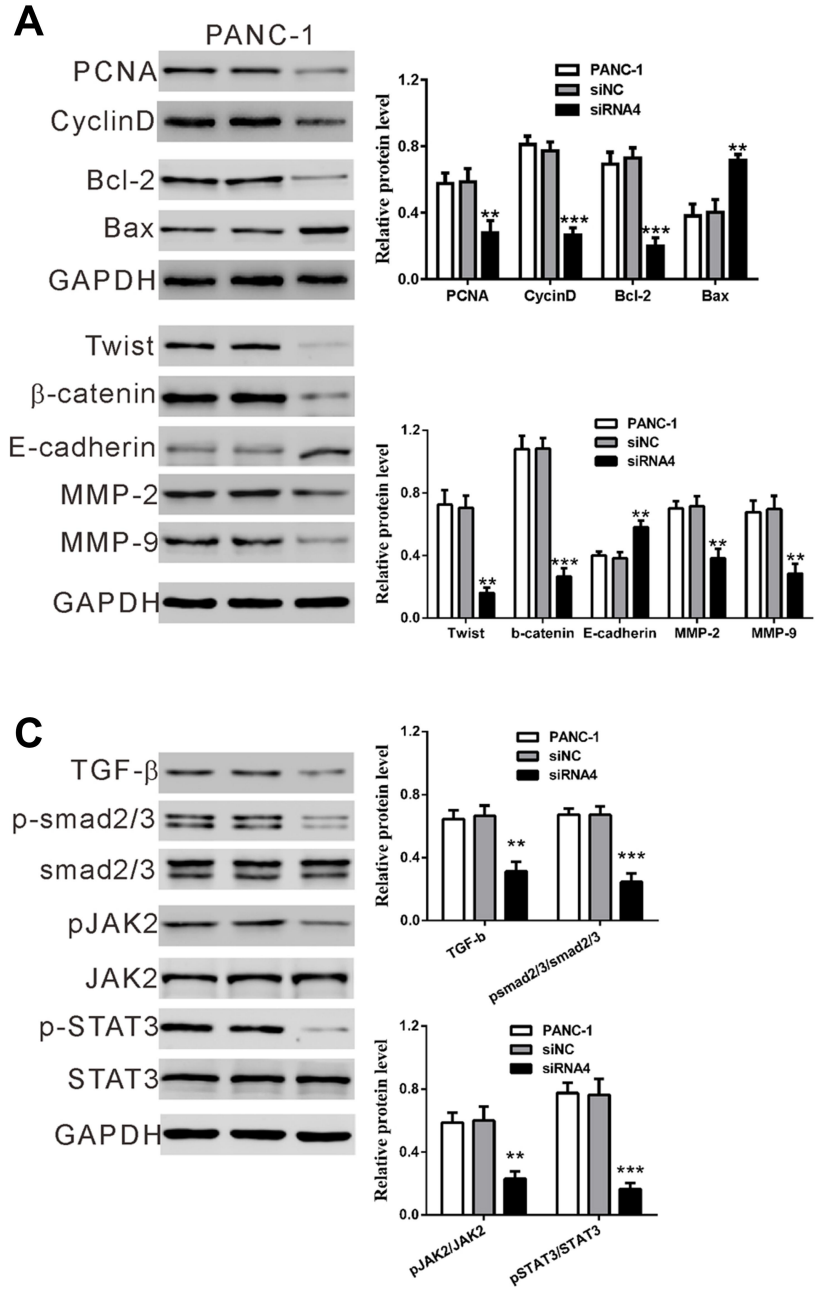

B
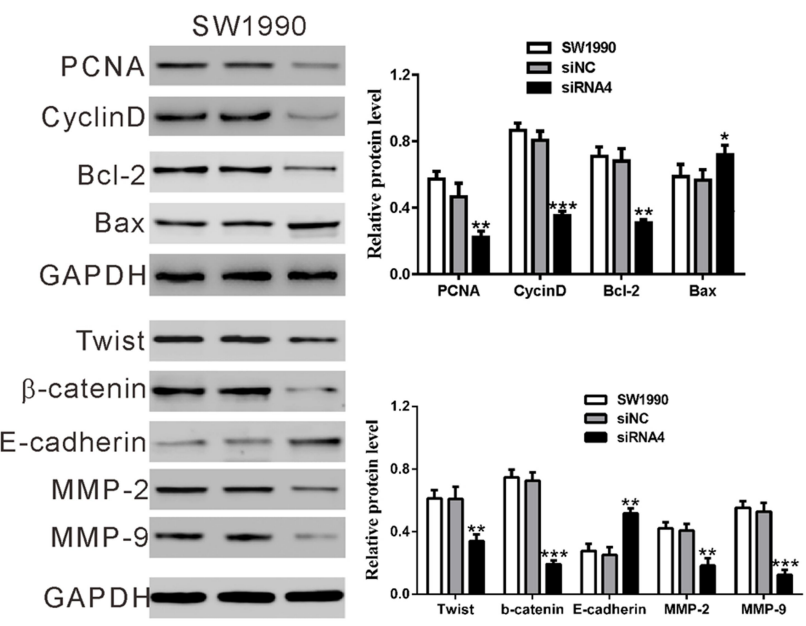

D
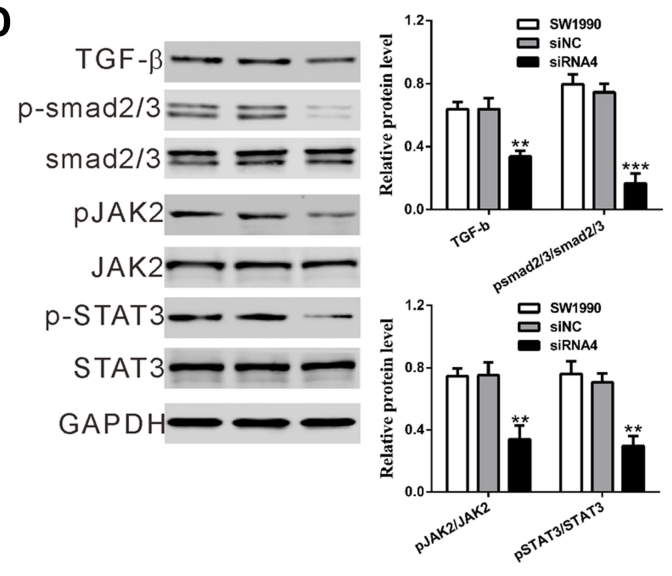

Figure 4 Mechanisms underlying LncRNA BC0379I6 functions. (A and B) Expression of key molecules in cell growth, apoptosis, metastasis and EMT was determined by Western blotting in BC037916 knockdown cells. (C and D) TGF- $\beta$ expression, and phosphorylation of smad 2/3, JAK2 and STAT3 was assessed. Left panel, representative images; right panel, relative expression levels to GAPDH. $* P<0.05, * * P<0.01$ and $* * * P<0.00$ Ivs siNC.

BC037916 (Figure 5A and Supplemental Figure S2A). qRTPCR analysis showed that BC037916 knockdown increased the expression of miR-3145-3p (Figure 5B), but had little effect on miR-4482-3p and miR-12,136 expression (Supplemental Figure S2B and 2C).

We then explored whether miR-3145-3p targeted the above downstream genes affected by lncRNA BC037916. By using TargetScan (http://www.targetscan.org/), Twist, the EMT related marker was found as the only potential target of miR-3145-3p (Figure 5C). In qRT-PCR analysis, miR-3145-3p mimic significantly suppressed Twist expression in PANC-1 and SW1990 cells (Figure 5D). Further luciferase reporter assay showed that miR-3145-3p mimic inhibited luciferase activity of Twist 3'UTR (WT), but had no effects on that of mutant 3'UTR (Figure 5E). These data suggested that miR-3145-3p directly bound to Twist 3'UTR, which resulted in decreased Twist expression.
We then explored whether inhibition of miR-3145-3p could reverse BC037916 knockdown-decreased Twist expression. As expected, downregulation of miR-3145-3p with miR-3145-3p inhibitor efficiently reversed the inhibition of Twist mRNA (Figure 5F) and protein levels (Figure 5G) by BC037916 knockdown. These analyses show that BC037916 promoted Twist expression through downregulating miR-3145-3p.

\section{BC0379I6 Knockdown Suppressed}

\section{Tumor Growth in Nude Mice}

Xenograft experiments were conducted to verify the effect of lncRNA BC037916 in vivo. As shown in Figure 6A, BC037916 knockdown in SW1990 cells significantly reduced tumor burden. At 46 days after cell injection, the average weight of tumors established from BC037916 
A C

3'-guuaagguuugugagu UUUAUAG a-5' hsa-miR-3145-3p 3'-guuaagguuugugaguUUUAUAGa-5' hsa-miR-3145-3p IIIIIII 5'-.. ttaaactttttattatat AAAT ATC a...-3'

B

PANC-1

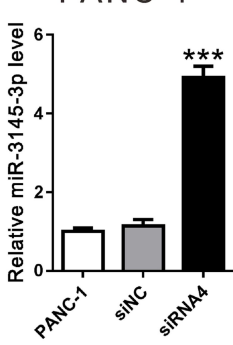

E

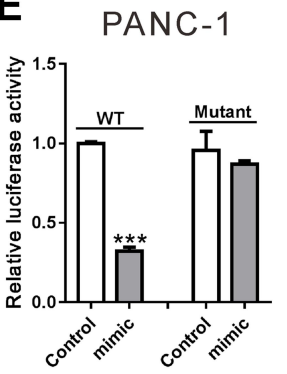

SW1990

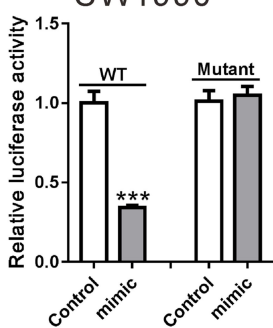

SW1990

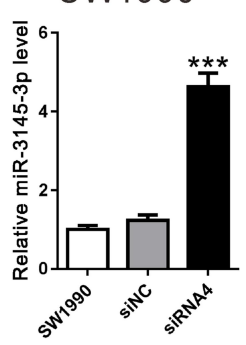

$\mathbf{F}$

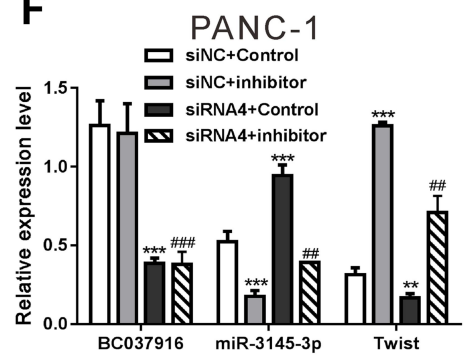

SW1990

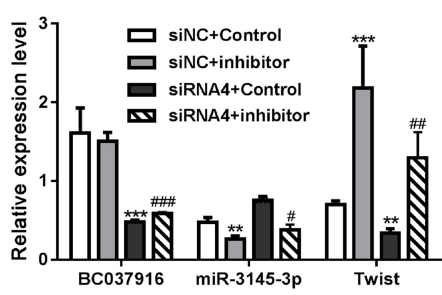

IIIIII

5 ' ..ttatgattgtttgtAAA TA TCut...-3' Twist UTR

D
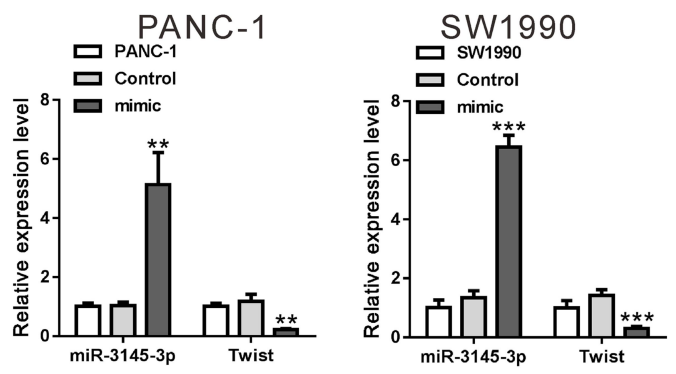

G

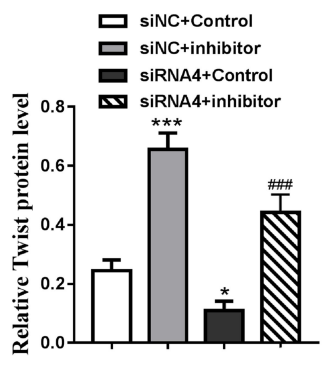

GAPDH

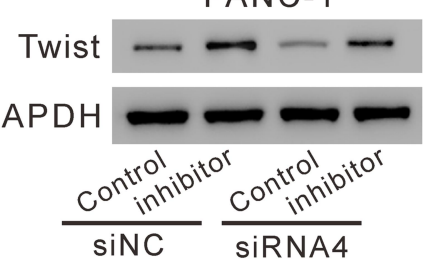

PANC-1

SW1990

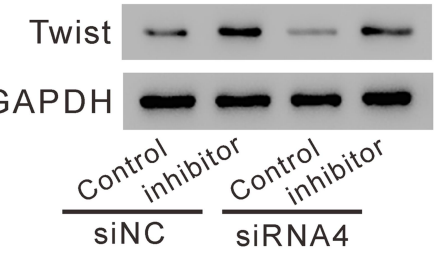

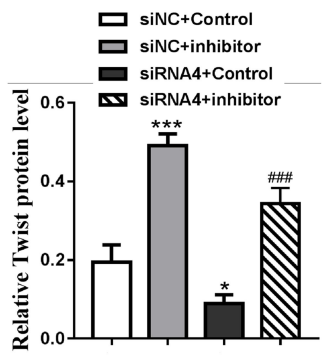

Figure 5 BC0379I6 positively regulated the expression of Twist through miR-3I45-3p. (A) Putative binding site of BC0379I6 with miR-3I45-3p, as predicted by FINDTAR3. (B) PANC-I and SWI990 cells transfected with control siRNA (siNC) or BC0379I6 siRNA (siRNA4), and miR-3I45-3p expression was detected by qRTPCR. $* * * P<0.00$ Ivs siNC. (C) Putative binding site of Twists 3'UTR with miR-3I45-3p, as predicted by TargetScan. (D) PANC-I and SWI990 cells were transfected with miR-3 I45-3p mimic or mimic control, and Twist mRNA expression was detected by qRT-PCR. $* * P<0.01$ and $* * * P<0.00$ I vs control. (E) Relative luciferase activities of Twists 3'UTR (WT and mutant) reporter in PANC-I and SWI990 cells transfected with miR-3145-3p mimic or control. (F and G) PANC-I and SWI990 cells were transfected with siNC/siRNA4, and miR-3 I45-3p inhibitor/control, and Twist mRNA (F) and protein levels (G) were detected by qRT-PCR and Western blotting, respectively. $* P<0.05$, $* * P<0.01$ and $* * * P<0.00 I$ vs siNC+control. ${ }^{\#} P<0.01$ and ${ }^{\# \#} P<0.00$ Ivs siRNA4+control.

knockdown cells was $45.5 \%$ lower as compared with that from control cells (Figure 6B). BC037916 expression decreased $77.2 \%$ in tumors derived from BC037916 knockdown cells (Figure 6C). These results indicated that downregulation of $\mathrm{BC} 037916$ hampered tumor growth in vivo. Western blotting confirmed that PCNA, Twist, and $\beta$-catenin expressions were also significantly decreased, and E-cadherin was remarkably increased in tumors derived from BC037916 knocked down cells (Figure 6D).

\section{Discussion}

Gene expression profiles using microarray analyses have provided genome-wide biological information to help distinguish the pancreatic cancer subtypes. ${ }^{27-30}$ LncRNAs, as a novel class of functional molecules involved in the development and progression of cancer, may also supply valuable information to reveal the mechanisms of the progression of pancreatic cancer. ${ }^{12,19-21}$ In this study, we identified BC037916 as the most significantly up-regulated lncRNA 
A

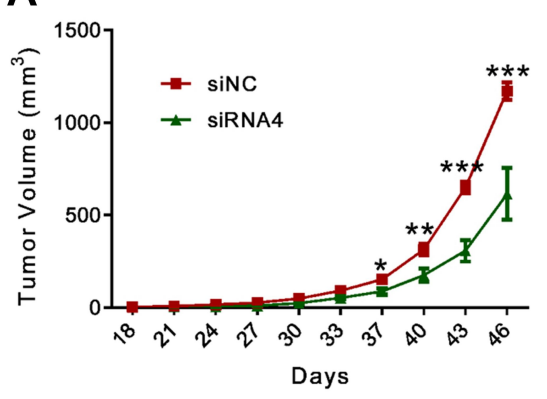

B

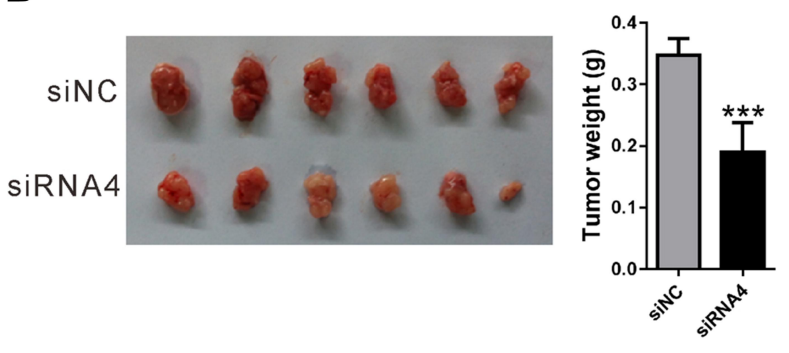

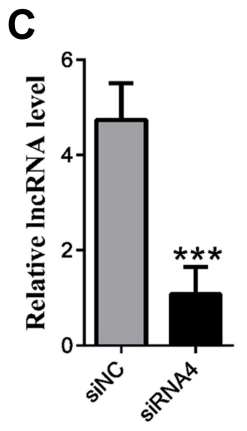

D
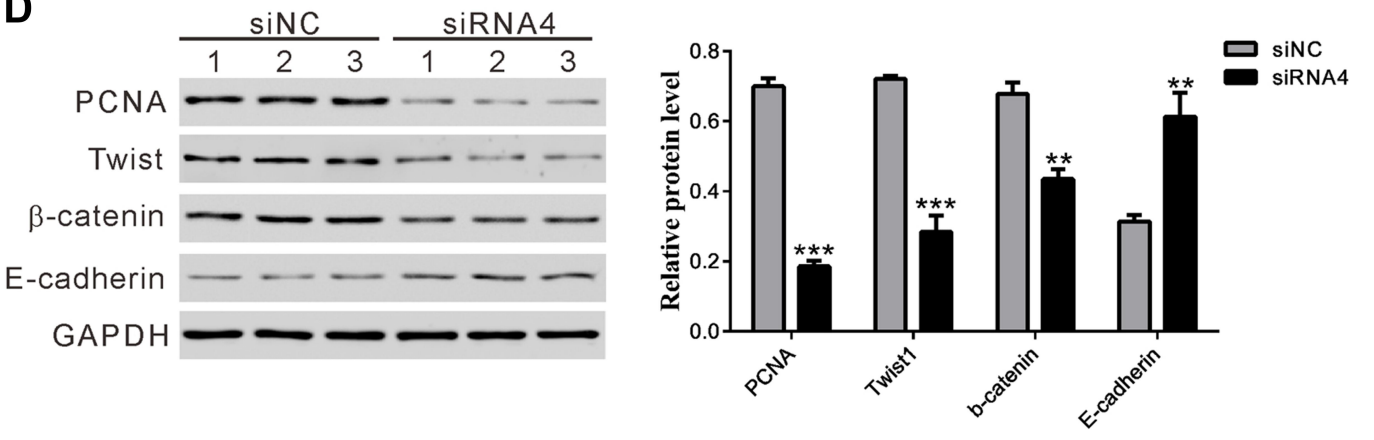

Figure 6 BC037916 Knockdown inhibited tumor growth in nude mice. SWI 990 cells transfected with siRNA4 or siNC were subcutaneously injected into nude mice ( $=6$ ). (A) Measurements of tumor volume were conducted every three days. (B) Tumors were collected at 46 days following transplantation. (C) BC0379I6 expression in xenograft from the nude mice. (D) Protein expression of PCNA, Twist, $\beta$-catenin and E-cadherin in transplanted tumors was determined by $W$ estern blot. $* P<0.05$, $* * P<0.01$ and $* * * P<0.001$ vs siNC.

in pancreatic cancer tissues by GATExplorer on publicly available datasets. BC037916, a novel lncRNA transcript, was previously recognized as a Homo sapiens cDNA clone. $^{31}$ The biological functions of lncRNA BC037916 remain unknown. In the present study, we confirmed that lncRNA BC037916 is extremely elevated in 86 pancreatic cancer tissues, compared with normal tissues (Figure 1). The relationship between BC037916 expression levels and certain clinicopathologic parameters was then evaluated (Table 1). Our study revealed that BC037916 expression in pancreatic cancer was related to the clinical stage, primary tumor, and regional lymph node invasion. Importantly, Kaplan-Meier survival curves (Figure 1E) and univariate analysis (Table 2) showed increased BC037916 expression was remarkably correlated with poor OS rate of pancreatic cancer patients. Multivariate analysis implied BC037916 as an independent risk indicator for poor prognosis of pancreatic cancer (Table 2). Collectively, our study suggests that BC037916 serves as a novel prognostic marker for pancreatic cancer patients.

Next, we characterized the biological functions of BC037916 by gain-of-function and loss-of-function experiments. We demonstrated that BC037916 facilitated cell proliferation, disrupted cell cycle progression, and facilitated cell invasion, but inhibited cell apoptosis in pancreatic cancer. BC037916 overexpression in CAPAN-1 cells induced G0/G1 arrest, suppressed cell apoptosis, and promoted cell proliferation, which suggested that increased cell growth may be ascribed to the suppressed cell apoptosis. This is the first study on the functional significance of BC037916 in pancreatic cancer, showing that BC037916 has oncogenic potential in the pancreatic cancer development.

lncRNAs have been suggested to promote cancer progression and metastasis by regulating the expression of protein-coding genes. $6,8,12$ We then determine whether lncRNA BC037916 regulates the protein expression of cancer-related molecules. As expected, our data suggested that knockdown BC037916 can modulate cell growth, apoptosis, metastasis, and EMT related factors, including down-regulating PCNA, Bcl-2, MMP-2, MMP-9, Twist, and $\beta$-catenin, as well as up-regulating Bax and E-cadherin (Figure 4). Currently, JAK/STAT signaling is responsible for regulating multiple cellular activities in tumorigenesis, such as cell cycle progression, apoptosis, angiogenesis, and tumor cell invasion. ${ }^{32}$ As a member of JAK/STAT signaling pathway, STAT3 is phosphorylated in response to extracellular signals. Once phosphorylated, STAT3 dimers translocate to the nucleus and activates the 
transcription of target genes. ${ }^{33}$ Constitutive activation of STAT3 is frequently found in various human tumors including pancreatic cancer. ${ }^{34-37}$ Moreover, TGF- $\beta$ signaling has been demonstrated to trigger EMT and promote tumor invasion. ${ }^{38}$ Here, we observed lower levels of TGF$\beta, \operatorname{psmad} 2 / 3, \mathrm{pJAK} 2$, and pSTAT3 in BC037916 knockdown cells than in control cells. Our data suggested that activity of JAK2/STAT3 and TGF- $\beta / \operatorname{smad} 2 / 3$ signaling pathways can be suppressed by BC037916 knockdown, which partially triggers cell proliferation, EMT, and invasion. Moreover, it has been recently shown that lncRNAs regulate miRNA targets by interfering with miRNA pathways. $^{26}$ Our study has shown that BC037916 knockdown increased the expression of miR-3145-3p, which may target Twist. Downregulation of miR-3145-3p efficiently reversed the suppression of Twist induced by BC037916 knockdown (Figure 5). Although our data suggested lncRNA BC037916 being an oncogene and targeting miR-3145-3p/Twist in pancreatic cancer, other direct downstream targets of BC037916 could not be ruled out. Therefore, further studies such as immunoprecipitation are needed to identify the proteins or microRNAs that directly bind to BC037916.

\section{Conclusion}

In summary, our findings suggested that lncRNA BC037916 could be a useful prognostic marker in pancreatic cancer patients. LncRNA BC037916 could promote cell proliferation and invasion via JAK2/STAT3 and TGF- $\beta /$ smad $2 / 3$ signaling in pancreatic cancer. Our findings demonstrate that $\mathrm{BC} 037916$ is a potential oncogene participating in pancreatic cancer pathogenesis.

\section{Abbreviations}

GEO, Gene Expression Omnibus; lncRNAs, long noncoding RNAs; AJCC, American Joint Committee on Cancer; OS, overall survival; qRT-PCR, quantitative real-time PCR; RNU6-1, U6 small nuclear 1; DMEM, Dulbecco's modified Eagle's medium; FBS, fetal bovine serum; HRP, horseradish peroxidase; ECL, enhanced chemiluminescence; FITC, fluorescein isothiocyanate; PI, propidium iodide; WT, wildtype; UTR, untranslated region fragment; SD, standard deviation; EMT, epithelial-mesenchymal transition.

\section{Data Sharing Statement}

The datasets used and/or analyzed during the current study are available from the corresponding author on reasonable request.

\section{Ethics Approval}

This study was approved by the Ethics Review Committee of People Hospital of Lishui, the Sixth Affiliated Hospital of Wenzhou Medical University (Zhejiang, China). Animal studies were conducted in compliance with the guidelines of the Animal Care and Use Committee of Fudan University Shanghai Cancer Center.

\section{Consent for Publication}

Not applicable.

\section{Acknowledgments}

This study was supported by grant from the National Natural Science Foundation of China (81573757).

\section{Disclosure}

The authors declare that they have no competing interests.

\section{References}

1. Siegel R, Ma J, Zou Z, Jemal A. Cancer statistics, 2014. CA Cancer J Clin. 2014;64(1):9-29. doi:10.3322/caac.21208

2. Ryan DP, Hong TS, Bardeesy N. Pancreatic adenocarcinoma. $N$ Engl J Med. 2014;371(11):1039-1049. doi:10.1056/ NEJMra1404198

3. The Lancet O. Pancreatic cancer in the spotlight. Lancet Oncol. 2014;15(3):241. doi:10.1016/S1470-2045(14)70097-X

4. Stathis A, Moore MJ. Advanced pancreatic carcinoma: current treatment and future challenges. Nat Rev Clin Oncol. 2010;7(3):163-172. doi:10.1038/nrclinonc.2009.236

5. Consortium EP. The ENCODE (ENCyclopedia Of DNA Elements) project. Science. 2004;306(5696):636-640.

6. Huang JL, Ren TY, Cao SW, et al. HBx-related long non-coding RNA DBH-AS1 promotes cell proliferation and survival by activating MAPK signaling in hepatocellular carcinoma. Oncotarget. 2015;6 (32):33791-33804. doi:10.18632/oncotarget.5667

7. Bida O, Gidoni M, Ideses D, Efroni S, Ginsberg D. A novel mitosis-associated lncRNA, MA-linc1, is required for cell cycle progression and sensitizes cancer cells to Paclitaxel. Oncotarget. 2015;6(29):27880-27890. doi:10.18632/oncotarget.4944

8. Liu Y, Zhao J, Zhang W, et al. IncRNA GAS5 enhances G1 cell cycle arrest via binding to YBX1 to regulate p21 expression in stomach cancer. Sci Rep. 2015;5:10159. doi:10.1038/srep10159

9. Yao J, Zhou B, Zhang J, et al. A new tumor suppressor LncRNA ADAMTS9-AS2 is regulated by DNMT1 and inhibits migration of glioma cells. Tumour Biol. 2014;35(8):7935-7944. doi:10.1007/ s13277-014-1949-2

10. Gupta RA, Shah N, Wang KC, et al. Long non-coding RNA HOTAIR reprograms chromatin state to promote cancer metastasis. Nature. 2010;464(7291):1071-1076. doi:10.1038/nature08975

11. Kino T, Hurt DE, Ichijo T, Nader N, Chrousos GP. Noncoding RNA gas5 is a growth arrest- and starvation-associated repressor of the glucocorticoid receptor. Sci Signal. 2010;3(107):ra8. doi:10.1126/ scisignal.2000568

12. Cheng Y, Jutooru I, Chadalapaka G, Corton JC, Safe S. The long non-coding RNA HOTTIP enhances pancreatic cancer cell proliferation, survival and migration. Oncotarget. 2015;6(13):10840-10852. doi:10.18632/oncotarget. 3450 
13. Nie Y, Liu X, Qu S, Song E, Zou H, Gong C. Long non-coding RNA HOTAIR is an independent prognostic marker for nasopharyngeal carcinoma progression and survival. Cancer Sci. 2013;104 (4):458-464. doi:10.1111/cas.12092

14. Sun J, Chen X, Wang Z, et al. A potential prognostic long non-coding RNA signature to predict metastasis-free survival of breast cancer patients. Sci Rep. 2015;5:16553. doi:10.1038/srep16553

15. Tsai MC, Spitale RC, Chang HY. Long intergenic noncoding RNAs: new links in cancer progression. Cancer Res. 2011;71(1):3-7. doi:10.1158/0008-5472.CAN-10-2483

16. Matouk IJ, DeGroot N, Mezan S, et al. The H19 non-coding RNA is essential for human tumor growth. PLoS One. 2007;2(9):e845. doi:10.1371/journal.pone.0000845

17. Nagano T, Fraser P. No-nonsense functions for long noncoding RNAs. Cell. 2011;145(2):178-181. doi:10.1016/j.cell.2011.03.014

18. Wilusz JE, Sunwoo H, Spector DL. Long noncoding RNAs: functional surprises from the RNA world. Genes Dev. 2009;23 (13):1494-1504. doi:10.1101/gad.1800909

19. Kim K, Jutooru I, Chadalapaka G, et al. HOTAIR is a negative prognostic factor and exhibits pro-oncogenic activity in pancreatic cancer. Oncogene. 2013;32(13):1616-1625. doi:10.1038/ onc.2012.193

20. Pang EJ, Yang R, Fu XB, Liu YF. Overexpression of long non-coding RNA MALAT1 is correlated with clinical progression and unfavorable prognosis in pancreatic cancer. Tumour Biol. 2015;36 (4):2403-2407. doi:10.1007/s13277-014-2850-8

21. Ellis BC, Molloy PL, Graham LD. CRNDE: A long non-coding RNA involved in cancer, neurobiology, and development. Front Genet. 2012;3:270. doi:10.3389/fgene.2012.00270

22. Derrien T, Johnson R, Bussotti G, et al. The GENCODE v7 catalog of human long noncoding RNAs: analysis of their gene structure, evolution, and expression. Genome Res. 2012;22(9):1775-1789. doi:10.1101/gr.132159.111

23. Pei H, Li L, Fridley BL, et al. FKBP51 affects cancer cell response to chemotherapy by negatively regulating Akt. Cancer Cell. 2009;16 (3):259-266. doi:10.1016/j.ccr.2009.07.016

24. Risueno A, Fontanillo C, Dinger ME. GATExplorer: genomic and transcriptomic explorer; mapping expression probes to gene loci, transcripts, exons and ncRNAs. BMC Bioinform. 2010;11:221. doi:10.1186/1471-2105-11-221

25. Pang KC, Stephen S, Engstrom PG, et al. RNAdb-a comprehensive mammalian noncoding RNA database. Nucleic Acids Res. 2005;33 (Databaseissue):D125-130.
26. Paraskevopoulou MD, Hatzigeorgiou AG. Analyzing miRNAlncRNA interactions. In: Long Non-Coding RNAs. Methods Mol Biol. 2016;1042:271-286.

27. Nakamura T, Furukawa Y, Nakagawa H, et al. Genome-wide cDNA microarray analysis of gene expression profiles in pancreatic cancers using populations of tumor cells and normal ductal epithelial cells selected for purity by laser microdissection. Oncogene. 2004;23 (13):2385-2400. doi:10.1038/sj.onc.1207392

28. Logsdon CD, Simeone DM, Binkley C, et al. Molecular profiling of pancreatic adenocarcinoma and chronic pancreatitis identifies multiple genes differentially regulated in pancreatic cancer. Cancer Res. 2003;63(10):2649-2657.

29. Harada T, Chelala C, Crnogorac-Jurcevic T, Lemoine NR. Genomewide analysis of pancreatic cancer using microarray-based techniques. Pancreatology. 2009;9(1-2):13-24. doi:10.1159/000178871

30. Grutzmann R, Saeger HD, Luttges J, et al. Microarray-based gene expression profiling in pancreatic ductal carcinoma: status quo and perspectives. Int J Colorectal Dis. 2004;19(5):401-413. doi:10.1007/ s00384-003-0563-3

31. Strausberg RL, Feingold EA, Grouse LH, et al. Generation and initial analysis of more than 15,000 full-length human and mouse cDNA sequences. Proc Natl Acad Sci U S A. 2002;99(26):16899-16903.

32. Greten FR, Karin M. Peering into the aftermath: jAKi rips STAT3 in cancer. Nat Med. 2010;16(10):1085-1087. doi:10.1038/nm1010-1085

33. Bowman T, Garcia R, Turkson J, Jove R. STATs in oncogenesis. Oncogene. 2000;19(21):2474-2488. doi:10.1038/sj.onc.1203527

34. Dhir R, Ni Z, Lou W, DeMiguel F, Grandis JR, Gao AC. Stat3 activation in prostatic carcinomas. Prostate. 2002;51(4):241-246. doi: $10.1002 /$ pros. 10079

35. Grandis JR, Drenning SD, Zeng Q, et al. Constitutive activation of Stat3 signaling abrogates apoptosis in squamous cell carcinogenesis in vivo. Proc Natl Acad Sci U S A. 2000;97(8):4227-4232. doi:10.1073/pnas.97.8.4227

36. Niu G, Bowman T, Huang M, et al. Roles of activated Src and Stat3 signaling in melanoma tumor cell growth. Oncogene. 2002;21 (46):7001-7010. doi:10.1038/sj.onc.1205859

37. Scholz A, Heinze S, Detjen KM, et al. Activated signal transducer and activator of transcription 3 (STAT3) supports the malignant phenotype of human pancreatic cancer. Gastroenterology. 2003;125 (3):891-905. doi:10.1016/S0016-5085(03)01064-3

38. Heldin CH, Landstrom M, Moustakas A. Mechanism of TGF-beta signaling to growth arrest, apoptosis, and epithelial-mesenchymal transition. Curr Opin Cell Biol. 2009;21(2):166-176. doi:10.1016/j. ceb.2009.01.021
OncoTargets and Therapy

\section{Publish your work in this journal}

OncoTargets and Therapy is an international, peer-reviewed, open access journal focusing on the pathological basis of all cancers, potential targets for therapy and treatment protocols employed to improve the management of cancer patients. The journal also focuses on the impact of management programs and new therapeutic

Submit your manuscript here: https://www.dovepress.com/oncotargets-and-therapy-journa agents and protocols on patient perspectives such as quality of life, adherence and satisfaction. The manuscript management system is completely online and includes a very quick and fair peer-review system, which is all easy to use. Visit http://www.dovepress.com/ testimonials.php to read real quotes from published authors. 